\title{
A therapeutic role for potassium $(K)$ to reduce pain and complications related to the cardiovascular system and bone in rheumatoid arthritis (RA): A clinical research perspective
}

\author{
Toktam Kianifard $^{\mathbf{1}^{*}}$, Arvind Chopra ${ }^{2}$ \\ ${ }^{1}$ Msc, PhD (Nutrition and Dietetics), Consultant, Center for Rheumatic Diseases, Pune, India \\ ${ }^{2} \mathrm{MD}, \mathrm{DNB}, \mathrm{FRCP}$, Director and Chief Rheumatologist, Center for Rheumatic Diseases, Pune, India
}

\begin{abstract}
Rheumatoid arthritis is a painful inflammatory disorder. Patients seek relief mostly with analgesics and anti-inflammatory drugs which are rife with life-threatening side effects. Alterations in the body's potassium (K) status may be one such factor. $\mathrm{K}$ along with sodium is critical to cellular homeostasis and the electrophysiology of nerve impulses. This review is based on the premise that $\mathrm{K}$ can be used therapeutically to reduce joint pain and inflammation in RA and co-morbidity. K ion channel inhibition was shown to cause persistent nerve stimulation (a prelude to pain sensation) and altered immunity ( $\mathrm{T}$ cells) in experimental studies. Diets rich in $\mathrm{K}$ (with normal/reduced salt intake) have to reduce hypertension in several large population studies. Premature atherosclerosis-related cardiovascular disorders and osteoporosis are important complications of RA. The third National Health and Nutrition Examination Survey (1994) carried out in the USA also reported hypokalemia in several RA patients. A diet deficient in K in RA patients was recently reported by an Indian study. In a controlled clinical trial (Iran), K supplementation (diet-based) led to a significant reduction in pain and arthritis in women suffering from seropositive RA. Some of the benefits of K in RA were postulated to be due to an improved cortisol status. K is not a known therapeutic agent in the treatment of RA. Vegetables and fruits are rich sources of $\mathrm{K}$ and provide a safe option for intervention. The existing data on the potential therapeutic role of $\mathrm{K}$ in RA is encouraging and merits further research.
\end{abstract}

Keywords: arthritis, diet, musculoskeletal pain, potassium, rheumatoid arthritis.

\section{Introduction}

RA is a chronic painful inflammatory arthritis with several potentially life-threatening complications. It causes a deterioration in quality of life and crippling deformities. Treatment is difficult $[1,2]$. The management of pain and inflammation increasingly depends on the use of analgesics, steroids, and nonsteroidal anti-inflammatory diseases (NSAID) and disease-modifying anti-rheumatic drugs (DMARD). However, these drugs come with many life-threatening side effects and toxicities [2].

There is a dire need to explore newer avenues to find safer management of RA. First, however, any other factors that contribute to pain and inflammation need to be identified. Non-pharmacological options such as diet-based approaches are promising adjunct treatments, but they have been neglected in the current guidelines [3, 4]. Though suspected for several decades to be beneficial, the precise role of potassium $(\mathrm{K})$ in RA is largely unknown [5].
In this study, it was hypothesized that patients suffering from RA are deficient in $\mathrm{K}$, and that $\mathrm{K}$ reduces joint pain and inflammation and complications pertaining to the cardiovascular and skeletal systems.

Multiple search strategies including Internet search engines (such as PubMed/Medline and Cochrane) and manual identification of suitable references were used. Leading investigators were contacted. Search results were discussed in pre-planned meetings with rheumatology colleagues (CRD, Pune). This article first presents a brief description of RA with special reference to its pathogenesis and the physiology of $\mathrm{K}$. This will enable the reader to recognize some of the physiological actions of $\mathrm{K}$ that may offset the pathological mechanism in RA. This is followed by an overview of the existing data that supports the hypothesis.

Objective: This article purposed to determine and describe the potential role of K in RA. Data (and the authors' interpretation) is presented to support the

\footnotetext{
* Corresponding author: Toktam Kianifard, Email: toktam_kiani81@yahoo.com, Tel: +98-917-507083222
}

Received: 07 December 2016; Accepted: 08 July 2017 
notion that (1) patients of RA may suffer from a K imbalance and/or deficiency; (2) a K imbalance and/or deficiency is likely to contribute to joint pain, cardiovascular morbidity, and osteoporosis; (3) a K imbalance and/or deficiency may have similar etiologies and pathogenesis, such as those postulated for a diet-induced proinflammatory state; (4) A Kenriched diet may be used safely by practitioners to augment the standard of care management in RA.

\section{Rheumatoid arthritis (RA)}

RA is reported worldwide with a prevalence of $1 \%$ [69]. However, COPCORD (Community-Oriented Program for Control of Rheumatic Diseases) population surveys, including Iran and India, have shown a lesser prevalence in the range of $0.3-0.5 \%$; that still means millions of patients in developing countries [10-12]. RA predominantly affects women and usually begins between the age of 40-60 years.

1. Etiology and Risk Factors. The exact cause of RA is not known. Several bacteria and viruses have been implicated but never proven [13]. Genetic predisposition is predominantly attributed to certain HLA D region alleles and shared epitope hypothesis $[14,15]$. Gene environment interactions are also described. Smoking is an established risk factor [16]. Dietary risk factors include the consumption of red meat and caffeine [17, 18]. Overweight or obese individuals may be at a higher risk [16].

1.2. Articular profile. RA is typically characterized by warm, painful, and swollen joints. The pain is often excruciating and often persists with frequent flares. RA is a symmetrical polyarthritis effecting small and large joints. Wrist and hands and feet are typically involved, but axial joints are usually spared. The disease causes crippling joint deformities and several systemic complications. Its course is generally progressive.

1.3. Extra-articular complications. RA is a systemic disease and effects several organ systems including bones, skin, lungs, the cardiovascular system, nervous system, eyes, abdomen, and kidneys. Patients often suffer from severe osteoporosis and fragility fractures. Premature atherosclerosis and coronary artery disease are leading causes of death [19]. Infections are common and can be fatal. The medications used to treat RA also contribute to morbidity and mortality by aggravating the immune suppressed status and damaging vital organs like the gut, liver, and kidneys.

1.4. Pathogenesis. RA is a prototypic autoimmune inflammatory disorder which predominantly targets the synovium. Subsequently, all structures in the joint and especially bones and cartilages are involved. The intense immune response, both cellular and humoral, is driven by abnormal immunological events. Though the precise inciting event is not known, it is likely to be a non-specific immune response to various antigenic triggers in a genetically predisposed individual. These triggers include infections, psychogenic stresses, and gene environment interactions (especially smoking and diet). Both innate and adoptive immune responses are intensely involved and continue in an exaggerated and uncontrolled manner. They operate in a vicious cycle to fuel the activation and proliferation of several immune cells. Macrophages, dendritic cells, $\mathrm{T}$ and $\mathrm{B}$ cells are among the several cells that participate in antigen (putative) presentation, copious cytokine production, and trafficking to the joints. Though considered predominantly a Th1 cytokine phenotype (gamma interferon, tumor necrosis factor, and interleukin 1) disorder, cytokines belonging to the Th2 (Interleukins 4 and 6) phenotype is also over-produced. Overall, there is an imbalance between Th1 and $\mathrm{Th} 2$. $\mathrm{T}$ cell responses are intensely driven by interleukins IL 2 and IL 17. Several other biochemical mediators like histamine, bradykinin, and prostaglandins pour into the system to promote inflammation (and pain) and facilitate several concurrent responses like that in the vascular (endothelial and blood flow) bed. $\mathrm{T}$ cells of the CD 4 phenotype, which express upregulated HLA DR, seem to be predominant in contrast to CD 8 cytotoxic T cells. There is an intense interaction between $\mathrm{T}$ cells and $\mathrm{B}$ cells. The $\mathrm{T}$ regulatory cell response is dampened. Tumor necrosis alfa (TNF- $\alpha$ ) seems to be the prime inflammatory cytokine that stimulates and drives several immune and inflammatory responses. It acts in concert with the potent pro-inflammatory cytokines IL 17 and IL 6. Overall, there is a failure to check and control immune inflammation despite several active countercheck mechanisms (including cytokines). All this leads to intense synovial and 
vascular tissue proliferation (called pannus) that causes bone damage (bone erosion and joint deformity) [20-23].

1.4.1. Autoantibodies [24-26]. Several antibodies are produced by stimulated B cells as a consequence of intense ongoing antigenic stimulation. Some of these antibodies mount a response to self-antigens (called molecular mimicry) in a breakdown of tolerance; chief among them are rheumatoid factor (RF) and anti-cyclic citrullinated peptide (CCP). These antibodies form antigen antibody complexes and bind activated complement. They interact with upregulated $\mathrm{FC} \gamma$ receptors on immune cells. This potentiates immune inflammatory responses.

1.4.2. Other Immune Target sites. Though synovium is the primary site, it is now believed that several other sites initiate and propagate immune inflammation. Best recognized are the oral gingiva, lung, and gut. Oral bacteria can stimulate formation of anti-CCP. Gut microbiome is emerging as a critical player for early immune events that eventually encompass the joint in a muchtargeted manner [27].

1.4.3. Other damage mechanisms. Several toxic molecules like reactive oxygen species (ROS) accumulate in RA to cause oxidant damage [28, 29]. Aberrant neuro-humoral endocrine axis responses, including altered steroid status and autonomic nervous stimulation, also aggravate immune inflammation [9]. It is generally believed that suppression of the hypothalamic pituitary adrenal axis in RA causes a reduction in steroid hormones which are highly potent immunosuppressives with pleotropic action on immune cells [30]. Recently, metabolic cellular mechanisms including abnormal glycolytic pathways have been found to link with dysfunctional immune cells [31].

1.5. Pharmacological Management. RA is essentially a clinical diagnosis. There is no single test to confirm the diagnosis [1, 3]; however, classification criteria ensure uniformity in diagnosis and are required for research and epidemiological studies [32]. The goals of treatment are to alleviate symptoms such as pain and swelling, control disease activity, prevent joint deformity, improve quality of life, and allow patients to maintain day-to-day functioning $[1,2]$.

1.5.1. Drugs. Pain relief is of utmost importance. "Treat pain or all else will fail" is an overarching clinical dictum, and treatment is achieved through the judicious use of analgesics (such as paracetamol and tramadol) and NSAIDs (such as diclofenac and naproxen). NSAIDs and steroids are potent anti-inflammatory agents and reduce joint swelling. However, modulation and suppression of the underlying immune inflammation lead to better control of the disease and are best achieved by long-term use of disease-modifying anti-rheumatic drugs (DMARDs), leading examples of which include methotrexate, hydroxychloroquine, sulfasalazine, and leflunomide. Nevertheless, in the last decade or so, the management of RA has been revolutionized by the advent of a new class of DMARD called biological response modifiers or simply biological agents [3335]. Biological agents are extremely precise target agents who generally engage and/or neutralize cytokines, receptors, or ligands. TNF $\alpha$, IL 6, B cells, and co-stimulatory ligands are some of the principle targets. Biological agents are generally monoclonal antibodies or fusion proteins that are chimeric or humanized. Several of them have been approved to treat RA; leading examples include infliximab, etanercept, abatacept, tocilizumab, and rituximab. In contrast to conventional DMARD which are slow-acting, biological agents produce early efficacy and lead to an overall better control of the disease and its complications. Both conventional and biological DMARD need careful screening (excluding infections and any organ system derangement) of patients prior to use and regular monitoring for efficacy and side effects.

1.5.2. Side Effects. The drugs used to treat RA are notorious for serious side effects that can damage practically every organ and system. These side effects can be life-threatening and uncommonly fatal. Analgesics and NSAID often lead to gastritis and acid- 
peptic disorders, and prolonged use can cause hepatic and renal derangement. Steroids cause water retention and edema, increased body weight, skin atrophy and easy bruisability, delayed wound healing and hirsutism. Metabolic derangements (diabetes), hypertension, osteoporosis, and infections are often reported by patients on steroid use. Being immunosuppressive, DMARD-including biological agents predispose patients to serious and difficultto-treat infections; tuberculosis and fungal infections are of serious concern (especially with biological agents). They rarely cause pulmonary, cardiac, or neurological complications and are implicated in malignancy.

1.6. Non-pharmacological Management [33]. Unfortunately, this aspect of the treatment of RA has been neglected both by doctors and the community. Counseling and health education are fundamental requirements. Patients suffer from several myths and misconceptions. Patients of RA are considered to consume an inadequate and unsuitable diet $[36,37]$. Patients follow several dos and don'ts which are often not advocated by doctors. This often causes malnutrition and anemia. None of the current standard guidelines on the management of RA provides comprehensive advice on diet. Patients are likely to benefit from a balanced diet rich in vegetables and fruits. Much evidence is available to support the benefits of following a Mediterranean diet and a diet rich in Omega oils [5]. Supervised exercise, physiotherapy, and rehabilitation are mandatory for optimum function and well-being.

\section{Potassium (K)}

2.1. Physiology. K, sodium, and calcium play integral roles in the electrophysiology of pain and myriad cellular functions. $\mathrm{K}$ is essential for the maintenance of cellular osmolality and homeostasis. $\mathrm{K}$ is an important micronutrient in health and actively participates in the normal function of several organ systems- neuromuscular, cardiovascular, endocrine, respiratory, and renal. It is also important in metabolic pathways, especially glucose-related enzymes [38, 39]. While sodium is predominantly extracellular (blood), $\mathrm{K}$ is intracellular. The sodium potassium ATPase (Na-K) pump is a carrier protein for the active (energy-consuming) transport of sodium and $\mathrm{K}$ across cell membranes. The total body $\mathrm{K}$ is considered to be about 3.5 gms; maximum tissue concentration is in the skeletal muscles [40]. Extracellular K is closely and dynamically regulated to maintain a plasma concentration of $4.2 \mathrm{mEq} / \mathrm{l}$ within a narrow range (usually 3.5 to $5.5 \mathrm{mEq} / \mathrm{l}$ ) of safety [41, 42]. Plasma assay is subjected to individual laboratory methods and several potential errors. Rapid K shifts across cell membranes are an important compensatory mechanism and can mask a body $\mathrm{K}$ deficit or excess. Abnormal levels (low or high) of plasma extracellular $\mathrm{K}$ can result from (i) dilution (administration of low $\mathrm{K}$ fluids) or concentration (dehydration); (ii) deranged $\mathrm{K}$ losses in urine or other body fluids; (iii) the transfer of $\mathrm{K}$ between cells and body fluids. Acid-base disturbances and hormones (especially insulin) are important drivers of cellular shifts. $\mathrm{K}$ is regulated by the kidneys though some excretion that may take place in stools and sweat. The loss of $\mathrm{K}$ through urine is driven by diet intake, acid base shifts, and several hormones (aldosterone, cortisol, renin, and angiotensin). Even during the total absence of diet $\mathrm{K}$ intake, there is an obligatory $\mathrm{K}$ loss by the kidneys.

2.2. $\mathrm{K}$ ion channels. $\mathrm{K}$ ion channels are widely distributed in various body cells. They regulate the cellular movement of $\mathrm{K}$ and abound in neurons and muscles, especially in nociceptors (pain perception sensors). They often work in concert with sodium and calcium ion channels. $\mathrm{K}$ channels along with the sodium-K ATP pump facilitate changes in plasma membrane and intracellular voltage (depolarization and repolarization, generation of action potential, and conductance of electrical impulse. Several types of channels are identified-voltage-gated potassium channels $(\mathrm{Kv})$, calcium activated $\mathrm{K}$ channels, two-pore $\mathrm{K}+$ channels, inwardlyrectifying $\mathrm{K}+$ channels, and $\mathrm{K}$ leak channels. [43-45].

2.2.1. Pain. Several experimental studies have demonstrated the role of $\mathrm{K}$ ion channels in abnormal pain signaling [46]. K deficiency (cellular) is considered to cause inhibition (closure) of $\mathrm{K}$ ion channels which leads to 
increased nerve stimulation and irritability [47]. Chronic pain is associated with abnormal sensory nerve excitability [14]. $\mathrm{Kv} 2$ is important in shaping central nervous system signaling, and its involvement in chronic pain was recently unraveled. Kv2 subunits are abundantly present in nociceptors and dorsal root ganglion in the spinal cord [48]. Kv4.2 was also shown to strongly modulate pain plasticity and related inflammation in spinal cord dorsal horn neurons [49]. The Kv7 (KCNQ or M channels) family was found to be widely expressed in the nervous system, including nociceptors. Intra-plantar injection of the $\mathrm{M}$ channel blocker XE991 into the hind paw of rats induced moderate pain, while peripheral injections of $\mathrm{M}$ channel enhancers (or 'openers') such as retigabine and flupirtine produced an analgesic effect [50]. Reduced Kv7 function was also involved in inflammatory pain. Diclofenac which is popularly used to treat pain and inflammation was demonstrated to activate Kv7.2/Kv7.3 channels [51].

2.2.2. Immunity and Other Effects. Calcium influx is pivotal in triggering several forms of intracellular signaling which causes the activation and proliferation of immune cells, including $\mathrm{T}$ cells which are important players in the pathogenesis of several autoimmune inflammatory disorders such as multiple sclerosis and RA (see above section 1.4). $\mathrm{K}$ ion channels provide $\mathrm{a}$ counterbalancing effect to the calcium (and sodium) movement into cells. $\mathrm{K}$ channels are also upregulated in memory $\mathrm{T}$ cells and can be modulated to produce beneficial immunological effects [15]. Clofazimine, which is now shown to inhibit voltage-gated $\mathrm{K}$ ion channels, has been used for several decades to treat leprosy, psoriasis, and discoid lupus erythematosus [52].

2.3. Disorders of deficit (hypokalemia) and excess (hyperkalemia). Both hypokalemia and hyperkalemia are medical emergencies. They are commonly encountered in critical care settings. If not diagnosed early and treated properly, they are fatal. An early abnormal K state is usually asymptomatic. Moderately severe deficiency or excess $\mathrm{K}$ causes symptoms that are ill-defined, non-specific, and often overlap (fatigue, muscle weakness, and muscle cramps). Heart rate abnormalities and arrhythmias are warning bells of impending crisis. Electrocardiography can provide diagnostic clues. Recognition of the medical circumstances (such as severe vomiting and diarrhea) that lead to such a $\mathrm{K}$ state is critical. While acute effects of $\mathrm{K}$ imbalance are well described (and researched), chronic effects are largely unknown. Moreover, it is not known whether minor shifts in plasma $\mathrm{K}$ within the normal range or total body $\mathrm{K}$ can cause any adverse physiological effects. In case of an acute $\mathrm{K}$ imbalance, the body attempts to rapidly compensate and restore normal plasma $\mathrm{K}$ mainly through cellular and renal mechanisms. However, in a chronic state, this may fail. Clinical recognition of this decompensation may be difficult in mild to moderate cases. It is likely that chronic $\mathrm{K}$ imbalance disorders are missed in clinical practice, because they are not primary disorders and are overshadowed by the primary disease. It is likely that chronic hypokalemia will lead to several adverse systemic effects on the basic health of an individual.

2.3.1. Hypokalemia. This is defined as a serum potassium concentration of less than 3.5 $\mathrm{mEq} / \mathrm{L}$. An assay of less than $2.5 \mathrm{mEq} / \mathrm{l}$ is critical and may cause death. Aggressive fluid replacement (usually saline) without due attention to the $\mathrm{K}$ requirement, severe vomiting and diarrhea, and excess diuresis are common causes seen in clinical practice. It would be unusual for low dietary intake to cause clinically discernible hypokalemia in healthy individuals; however, many longterm health risks are considered to be related to insufficient dietary potassium. Hypokalemia is also a feature of several other medical disorders, e.g., Cushing's syndrome, renal tubular acidosis, chronic hepatic disorders, hyperaldosteronism, acute alcoholism, heart failure, and Bartter's syndrome. Medications (diuretics, antidepressants, iodinated contrast agents) can also cause hypokalemia [53].

2.3.2. Hyperkalemia. This is defined as a plasma concentration greater than $5.5 \mathrm{mEq} / 1$. An assay of $7.5 \mathrm{mEq} / \mathrm{l}$ or higher is critical 
and may rapidly lead to severe cardiac arrhythmia and death. Metabolic abnormalities such as diabetes ketoacidosis and renal failure are common causes. Iatrogenic causes are important due to the inadvertent administration of excess $\mathrm{K}$ (oral and/or parenteral) [54-56].

2.3.3. Diet and Daily Requirement. Cereals, pulses, nuts, oil seeds, and fruits are important sources of $\mathrm{K}$. A natural diet can provide around 5-10 $\mathrm{g}$ of $\mathrm{K}$ (50-150 $\mathrm{mmol} / \mathrm{day}$ ). During the processing of foods, potassium is washed out and often replaced by sodium [5]. There is no evidence to suggest a difference between $\mathrm{K}$ foods with reference to better absorption or utilization. Vegetables contain an abundance of $\mathrm{K}$ phosphate salt. There is currently no global consensus on the recommended daily allowance for potassium. It is generally believed to be between $3.5 \mathrm{gm}$ to $5.6 \mathrm{gm}$ with men requiring a greater amount [57]. The WHO has recommended a potassium intake of at least $90 \mathrm{mmol} /$ day (3510 $\mathrm{mg} /$ day) for adults [58].

3. Potassium and RA. Overall, the clinical data regarding a correlation between potassium and RA is insufficient and sketchy. Several decades ago, Charles Weber (1974) strongly proposed a causal link between K deficiency and RA [59]. However, the first proposal of a possible link between a low dietary intake of $\mathrm{K}$ and $\mathrm{RA}$ and its dietary correction was comprehensively described by De Coti-Marsh [60, 61].

3.1. Body status. The Third National Health and Nutrition Examination Survey (NHANES III), 1988-94, in the USA carried out a household survey of 33,994 persons (aged 2 months and older) using a self-reporting questionnaire. Among the survey respondents, 840 reported suffering from RA [62]. Blood K assay reports were available for 691 RA patients and showed that $7.8 \%$ had less than $3.6 \mathrm{mEq} / \mathrm{l}, 34.7 \%$ between 3.6 and $4.0,40.7 \%$ between 4.0 and 4.4 , and $18.1 \%$ above $4.4 \mathrm{mEq} / \mathrm{l}$. The assays were not standardized. Based on this survey report, Weber (2001) opined that a more likely normal cutoff should be above $4.4 \mathrm{mEq} / \mathrm{l}$ and that only $18 \%$ of subjects suffering from RA in this survey were likely to have normal serum potassium levels [7]. Furthermore, he proposed that RA patients are likely to have low body K. In another hospital-based study from the UK, 14 biochemical estimations were performed on the serum of 100 consecutive in-patients suffering from RA and 100 age-matched control patients [63]. The mean values for sodium, potassium, and cholesterol (though within normal range) were significantly lower in patients with RA. Low salivary K levels were also reported [64]. In a recent Indian study, a comprehensive diet survey was carried out with 139 RA patients on the standard of care therapy and 165 unrelated healthy control subjects [53, 65]. The various dietary parameters were collected over a 10-day record (diet diary). The dietary $\mathrm{K}$ content of RA patients was significantly lower than that of the healthy controls $(\mathrm{p}<0.001)$. The mean daily dietary $\mathrm{K}$ was $1238.7 \mathrm{mg}$ in RA patients and $3334.9 \mathrm{mg}$ controls; corresponding values were $1651.2 \mathrm{mg}$ and $3438.8 \mathrm{in}$ men and $1161.3 \mathrm{mg}$ and 3170.9 in women. Other major dietary constituents such as protein, fats, carbohydrates, and sodium were well matched with national Indian standards. The authors concluded that the diet of RA patients was grossly deficient for $\mathrm{K}$ and that this was likely to be due to food fads and misconceptions in the community [66]. The precise cause of low potassium in RA is unknown. Diet may be an important cause in some patients as described above [65]. However, other causes may be speculated based on the pathophysiology events in RA which may be linked with body K. RA is characterized by a higher than normal metabolic rate and catabolic state which lead to cachexia, low muscle mass, an acid load, and disturbed $\mathrm{pH}$ balance [67]. Compensatory changes in cellular $\mathrm{K}$ and renal excretion $(\mathrm{K})$ are required to maintain neutral $\mathrm{pH}$. Due to intense immune cellular activity, increased metabolic demand, and energy expenditure, the glycolytic pathways are intensely activated. $\mathrm{K}$ is required for several enzymes (glucose phosphate isomerase, enolase, and aldolase) which participate in the glycolytic pathway [68-70]. It is probable that these hyperactive states require excess $\mathrm{K}$, and thus, there is an overutilization of K. In RA patients, there may be a relative (intracellular due to electrolyte shifts) or absolute deficiency of body $\mathrm{K}$. It is prudent to add that there is an important 
relationship between $\mathrm{K}$ and cortisol status [61, 71]. RA is a low-cortisol state disorder (see below) which may be age aggravated by low body K. Low cortisol in turn also leads to low body $\mathrm{K}$ and hypokalemia.

3.2. Experimental Data (pain and inflammation). Several mechanisms contribute to the intensity and nature of chronic pain in RA. Small nerve endings and fibers are entrapped in inflammatory synovitis to impart a neurogenic or neuropathic component. Blocking $\mathrm{K}$ ion channels was demonstrated to reduce arthritis in animal models. In the pristine-induced arthritis model using Dark Agoti rats, 21 days of treatment with ShK-L5-amide significantly decreased the number of affected joints and reduced the severity of radiological and histopathological findings [72]. CD4 and CD8 T lymphocytes are important in the pathogenesis of RA, and their activity has been reported to be critically dependent on constitutively-expressed $\mathrm{K}$ ion channels (K2pore5.1 type) [73]. T cells isolated from the synovial fluid of patients with RA were characterized as mainly Kv1.3 high CCR7 [21]. Experimental evidence supports the inhibitory effects of serum $\mathrm{K}$ on free radical formation and-oxidant damage [74]. However, the relationship between dietary $\mathrm{K}$ and $\mathrm{K}$ ion channels has not been investigated.

3.3. Clinical data. Nuki et al. (1970) demonstrated shifts in body $\mathrm{K}$ in 8 patients of RA who were prescribed oral $\mathrm{K}$ supplements in a 30-day interventional study; a detailed diet analysis was carried out [75, 76]. Patients were also treated with adreno-corticotrophic hormone or a diuretic (spironolactone) during the latter half of the study. Total body potassium (TBK) was estimated using the radio-isotope technique and found to be low at baseline. TBK remained constant throughout the study, and therefore, serum $\mathrm{K}$ changes were likely to be caused be a cellular shift. The authors postulated that changes in serum $\mathrm{K}$ were due to renal compensatory mechanisms (likely renin angiotensin aldosterone) to the $\mathrm{K}$ load. Rastamanesh et al. (2009) demonstrated a significant reduction in pain and inflammatory arthritis induced by oral $\mathrm{K}$ supplementation. Thirty-six female patients suffering from active seropositive RA were enrolled in a 28-day randomized double-blind, placebo-controlled intervention trial conducted in Iran. Concurrent stable treatment with corticosteroids and/or DMARD was permitted. Patients were permitted to continue their routine diet. $6 \mathrm{gm}$ of $\mathrm{K}$ salt (chloride) was administered in grape juice daily to 16 patients, while plain grape juice was consumed by 16 patients in the placebo arm. The total mean potassium daily intake was $1540 \mathrm{mg}$ in the placebo group and $6495 \mathrm{mg}$ in the active arm. The $\mathrm{K}$ supplement was well tolerated and none reported side effects [61]. Both Weber (2010 and Rastmanesh (2009) postulated that K mediates its clinically beneficial effect principally by modulating the hypothalamic-pituitary-adrenal (HPA) axis [77, 78]. The HPA axis is known to be impaired in RA and influences immune inflammatory processes and electrolyte homeostasis [71, 77, 78]. A disconnect has also been described between HPA and the sympathetic adrenal system [71].

3.4. Effect on Cardiovascular System. Several population-based studies have validated the benefits of a K-rich diet and $\mathrm{K}$ supplementation in the prevention and treatment of hypertension [79-82]. Though the exact mechanism is not known, several experimental studies have demonstrated the inhibitory effects of serum $\mathrm{K}$ on vascular smooth muscle proliferation, reducing macrophage adherence to the vascular wall, arterial thrombosis, free oxygen radicals, and reactive oxygen species [83-85]. $\mathrm{K}$ ions are also released by the endothelial cells in response to neuro-humoral mediators (sympatheticadrenal and cortisol related mechanisms) and physical forces (such as shear stress) and contribute to endothelium-dependent relaxations. Though the response is believed to be slow and modest, potassium supplements lower blood pressure. Thus, $\mathrm{K}$ is beneficial for cardiovascular health and blood flow which is of great importance in patients suffering from RA. Cardiovascular complications are the leading cause of premature death in RA [11, 86].

3.5. Effect on Bone. Fruit and vegetable intake may protect against premenopausal bone loss [8792]. The benefit of diet $\mathrm{K}$ on bone strength was shown in a long-term follow-up of a Framingham Study cohort [93]. The beneficial effect of potassium is explained by the theory 
that a vegetable and fruit diet which is rich in alkaline salts protects the bone. This is in contrast to the Western type of non-vegetarian diet which has acidic metabolites requiring alkaline salts from the bone to maintain $\mathrm{pH}$ balance [94, 95]. However, the role of the skeleton in regulating $\mathrm{pH}$ is debatable. $\mathrm{K}$ intake has been shown to be associated with reduced urinary calcium excretion [88].

3.6. Diet Intervention (RA). The nutritional status of RA patients appears to be compromised despite adequate intake [65]. Although there is no ideal "RA diet" that can treat the condition, some foods may help lower inflammation. These foods include fruits and vegetables, whole grains, olive oil, and fish. Though this was supported by several clinical studies, the overall data was found to be rather sparse and dismal in a Cochrane review [42, 96, 97]. A Mediterranean diet rich in Omega oils has provided the best evidence of a reduction in pain and arthritis. A recent review summed up by stating that an integrative approach which includes a Mediterranean-style diet with probiotics may be useful in the long-term management of RA $[11,96]$. It is interesting to note that the diets used in the studies of RA were essentially vegetarian and likely to have been rich in $\mathrm{K}$, but this aspect was not analyzed.
4. Concluding Remarks. Though the overall data on the therapeutic role of $\mathrm{K}$ in RA is inadequate, it is encouraging. Further research is required to establish the role of $\mathrm{K}$ as an adjunct therapy in RA. There are several benefits of $\mathrm{K}$ in health which could be extrapolated to be relevant in the overall management of RA. The data presented in the current report supports an analgesic and antiinflammatory effect of $\mathrm{K}$. The benefits on cardiovascular and bone health are indeed a bonus in RA. Newer data is emerging. Kv1.3 (ion channel) blockers are described to have a potential in the treatment of RA and other chronic autoimmune disorders [46]. Diet is a safer option to administer $\mathrm{K}$ rather than medicinal salt (potassium chloride). Doctors should be encouraged to advocate diets rich in vegetables and fruits to patients suffering from RA.

This work was not funded by any organization or research grant. Both authors contributed equally to the review paper. Several colleagues in the Centre for Rheumatic Diseases, Pune contributed useful discussion to the current subject.

\section{Conflicts of interest}

The author declares no conflicts of interest.

\section{References}

1. Pincus $\mathrm{T}$, Yazici $\mathrm{Y}$, Sokka $\mathrm{T}$, Aletaha D, Smolen JS. Methotrexate as the "anchor drug" for the treatment of early rheumatoid arthritis. Clin Exp Rheumatol 2003; 21(5 Suppl 31): S179-85.

2. Ramiro S, Machado P, Singh JA, Landewé RB, da Silva JAP. Applying science in practice: the optimization of biological therapy in rheumatoid arthritis. Arthritis research \& therapy 2010; 12(6): 220. doi: 10.1186/ar3149.

3. Aletaha D, Neogi T, Silman AJ, Funovits J, Felson DT, Bingham CO. et al. 2010 rheumatoid arthritis classification criteria: an American College of Rheumatology/ European League Against Rheumatism collaborative initiative. Arthritis \& Rheumatism 2010; 62(9): 2569-81. doi: 10.1136/ard.2010 138461.
4. O'Dell JR, Mikuls TR, Taylor $\mathrm{TH}$, Ahluwalia V, Brophy M, Warren SR. et al. Therapies for active rheumatoid arthritis after methotrexate failure. $\boldsymbol{N}$ Engl $\boldsymbol{J}$ Med 2013; 369(4): 307-18. doi: 10.1056/NEJMoa1303006.

5. CE W. Potassium Nutrition. Bloomington. Inc, I Universe; 2011.

6. Chopra A. The COPCORD world of musculoskeletal pain and arthritis. Rheumatology (Oxford) 2013; 52(11): 1925-8. doi: 10.1093/rheumatology/ ket222.

7. Chopra A, Saluja M, Patil J, Tandale HS. Pain and disability, perceptions and beliefs of a rural Indian population: A WHO-ILAR COPCORD study. WHOInternational League of Associations for Rheumatology. Community Oriented Program for Control of Rheumatic Diseases. $\boldsymbol{J}$ Rheumatol 2002; 29(3): 614-21.
8. Chopra A, Patil J, Billempelly V, Relwani J, Tandle HS. Prevalence of rheumatic diseases in a rural population in western India: a WHO -ILAR COPCORD Study. J Assoc Physicians India 2001; 49: 240-6.

9. Shah A. Harrison's Principle of Internal Medicine 18th ed edn. McGraw Hill.

10. Chopra A, Ghorpade R, Sarmukkadam S, Joshi V, Mathews AJ, Gauri L. et al. A staggering burden of pain and rheumatic disorders in India: A national bone \& joint decade India community oriented program for control of rheumatic disease survey 2006-2011. Arthritis \& Rheumatism 2012; 64: S23-S24.

11. Chopra A. Disease burden of rheumatic diseases in India: COPCORD perspective. Indian Journal of Rheumatology 2015; 
10(2): 70-77. doi: 10.1016/j.injr. 2015.04.002.

12. Chopra A, Ghorpade R, Sarmukkadam S, Joshi V, Mathews AJ, Gauri L. et al. 5 million patients and not $0.34 \%$ is worrisome: burden of rheumatoid arthritis in India based on a bone and joint decade India community oriented program for control of rheumatic disease. Arthritis \& Rheumatism 2012; 64: S23.

13. Plenge RM, Raychaudhuri S. Leveraging human genetics to develop future therapeutic strategies in rheumatoid arthritis. Rheumatic Disease Clinics of North America 2010; 36(2): 25970. doi: 10.1016/j.rdc.2012.03. 002.

14. Hameed $\mathrm{K}$, Bowman $\mathrm{S}$, Kondeatis E, Vaughan R, Gibson $T$. The association of HLA-DRB genes and the shared epitope with rheumatoid arthritis in Pakistan. Rheumatology 1997; 36(11): 1184-88. doi: 10.1093/ rheumatology/36.11.1184.

15. Scott DL, Wolfe F, Huizinga TW Rheumatoid arthritis. Lancet 2010; 376(9746): 1094-108. doi: 10.1016/s0140-6736 (10)60826-4.

16. Kianifard.T. Dissertation, The effect of potassium supplement on pain in Rheumatoid Arthritis. 2015.

17. Pattison DJ, Symmons DP, Lunt M, Welch A, Luben R, Bingham SA. et al. Dietary risk factors for the development of inflammatory polyarthritis: evidence for a role of high level of red meat consumption. Arthritis \& Rheumatism 2004; 50(12): $3804-$ 12. doi: 10.1002/art.20731.

18. Oliver J, Silman A. Risk factors for the development of rheumatoid arthritis. Scandinavian Journal of Rheumatology 2006; 35(3): 16974. doi: $10.1080 /$ 03009740600718080.

19. Simon JA, Hudes ES. Relation of ascorbic acid to bone mineral density and self-reported fractures among US adults. American Journal of Epidemiology 2001; 154(5): 427-33. doi: 10.1093/aje/154.5.427.

20. McInnes IB, Schett G. The pathogenesis of rheumatoid arthritis. New England Journal of Medicine 2011; 365(23): 2205-
19. doi: 10.1056/NEJMra 1004965

21. Wulff H, Castle NA, Pardo LA Voltage-gated potassium channels as therapeutic targets. Nature reviews Drug Discovery 2009; 8(12): 982-1001. doi: 10.1038/ nrd2983. doi: 10.1038/ki.1980. 11.

22. Schambelan M, Sebastian A, Biglieri EG, Brust NL, Chang BC, Hirai J. et al. Prevalence, pathogenesis, and functional significance of aldosterone deficiency in hyperkalemic patients with chronic renal insufficiency. Kidney International 1980; 17(1): 89101.

23. Sköldstam L, Hagfors L, Johansson G. An experimental study of a Mediterranean diet intervention for patients with rheumatoid arthritis. Annals of the Rheumatic Diseases 2003; 62(3): 208-14.

24. Pincus T, Callahan LF. What is the natural history of rheumatoid arthritis? Rheum Dis Clin North Am 1993; 19(1): 123-51.

25. Jensen MP, Karoly P, Harris P. Assessing the affective component of chronic pain: development of the Pain Discomfort Scale. J Psychosom Res 1991; 35(2-3): 149-54. doi: 10.1016/0022-3999(91)90069-z.

26. Staron A, Makosa G, KoterMichalak M. Oxidative stress in erythrocytes from patients with rheumatoid arthritis. Rheumatol Int 2012; 32(2): 331-4. doi: 10. 1007/s00296-010-1611-2.

27. Gumz ML, Rabinowitz L, Wingo CS. An integrated view of potassium homeostasis. New England Journal of Medicine 2015; 373(1): 60-72. doi: 10.1056/NEJMx150027.

28. Silva G, Reis B, Cozzolino S. Micronutrients deficiencies in rheumatoid arthritis patients. Int J Pathol Clin Res 2016; 2: 029.

29. Cerhan JR, Saag KG, Merlino LA, Mikuls TR, Criswell LA. Antioxidant micronutrients and risk of rheumatoid arthritis in a cohort of older women. American Journal of Epidemiology 2003; 157(4): 345-54. doi: 10.1093/aje/ kwf205.

30. Lin C, Boltz R, Blake J, Nguyen M, Talento A, Fischer P. et al.
Voltage-gated potassium channels regulate calcium-dependent pathways involved in human $\mathrm{T}$ lymphocyte activation. The Journal of Experimental Medicine 1993; 177(3): 637-45. doi: 10.1084/jem.177.3.637.

31. Maingret F, Coste B, Padilla F, Clerc N, Crest M, Korogod SM. et al. Inflammatory mediators increase Nav1. 9 current and excitability in nociceptors through a coincident detection mechanism. The Journal of General Physiology 2008; 131(3): 211-25. doi: 10.1085/jgp. 200709935.

32. Mota LMHd, Cruz BA, Brenol CV, Pereira IA, Fronza LSR, Bertolo MB. et al. 2011 Consensus of the Brazilian society of rheumatology for diagnosis and early assessment of rheumatoid arthritis. Revista Brasileira de Reumatologia 2011; 51(3): 207-19.

33. Christie A, Jamtvedt G, Dahm KT, Moe RH, Haavardsholm EA, Hagen KB. Effectiveness of nonpharmacological and nonsurgical interventions for patients with rheumatoid arthritis: an overview of systematic reviews. Physical Therapy 2007; 87(12): 1697. doi: $10.2522 / \mathrm{ptj}$. 20070039.

34. Singh JA, Furst DE, Bharat A, Curtis JR, Kavanaugh AF, Kremer JM. et al. 2012 Update of the 2008 American College of Rheumatology recommendations for the use of disease-modifying antirheumatic drugs and biologic agents in the treatment of rheumatoid arthritis. Arthritis care \& research 2012; 64(5): 625-39. doi: 10.1002/acr.21641.

35. Van Assen S, Agmon-Levin N, Elkayam O, Cervera R, Doran M, Dougados M. et al. EULAR recommendations for vaccination in adult patients with autoimmune inflammatory rheumatic diseases. Annals of the Rheumatic Diseases 2011; 70(3): 414-22. doi: 10.1136/ard.2010.137216.

36. Lacapere J, Bennett N, Dupont Y, Guillain F. pH and magnesium dependence of ATP binding to sarcoplasmic reticulum ATPase. Evidence that the catalytic ATPbinding site consists of two domains. Journal of Biological 
Chemistry 1990; 265(1): 348-53.

37. Jorgensen PL, Håkansson KO, Karlish SJ. Structure and mechanism of $\mathrm{Na}$, K-ATPase: functional sites and their interactions. Annual review of physiology 2003; 65(1): 817-49. doi: 10.1146/annurev.physiol.65. 092101.142558.

38. Holbrook JT, Patterson K, Bodner J, Douglas L, Veillon C, Kelsay J. et al. Sodium and potassium intake and balance in adults consuming self-selected diets. The American Journal of Clinical Nutrition 1984; 40(4): 786-93. doi: 10.1016/0889-1575 (92)90027-h.

39. Giebisch G, Krapf R, Wagner C. Renal and extrarenal regulation of potassium. Kidney Int 2007; 72(4): 397-410. doi: 10.1038/ sj.ki.5002288.

40. Ericsson F. Potassium in Skeletal Muscle in Untreated Primary Hypertension and in Chronic Renal Failure, Studied by X-ray Fluorescence Technique. Acta Medica Scandinavica 1984; 215(3): 225-30. doi: 10.1111/j. 0954-6820.1984.tb04998.x.

41. Marino PL: The ICU Book, Baltimore. Philadel Phia. In. Williams \& Wilkins. A Waverly Company; 1998. [http://www.nlm.nih.gov/medl. ineplus/vegetariandiet.html ].

42. Du X, Gamper N. Potassium channels in peripheral pain pathways: expression, function and therapeutic potential. Current Neuropharmacology 2013; 11(6): 621-40. doi: 10.2174/1570159 X113119990042.

43. Salkoff L, Butler A, Ferreira G, Santi C, Wei A. Highconductance potassium channels of the SLO family. Nature Reviews Neuroscience 2006; 7(12): 921-31. doi: 10.1038/nrn 1992.

44. Clark R, Proks P. ATP -sensitive potassium channels in health and disease. Adv Exp Med Biol 2010; 654: 165-92. doi: 10.1007/97890-481-3271-3_8.

45. Tsantoulas C, McMahon SB Opening paths to novel analgesics: the role of potassium channels in chronic pain. Trends Neurosci 2014; 37(3): 146-58. doi: 10.1016/j.tins.2013.12.002.

46. Mathie A. Ion channels as novel therapeutic targets in the treatment of pain. $\boldsymbol{J}$ Pharm Pharmacol 2010; 62(9): 1089-95. doi: $10.1111 / j .2042$ 7158.2010.01131.x.

47. Coetzee WA, Amarillo Y, Chiu J, Chow A, Lau D, McCormack T. et al. Molecular diversity of $\mathrm{K}+$ channels. Ann N Y Acad Sci 1999; 868: 233-85.

48. Linley JE, Rose K, Patil M, Robertson B, Akopian AN, Gamper N. Inhibition of $\mathrm{M}$ current in sensory neurons by exogenous proteases: a signaling pathway mediating inflammatory nociception. Journal of Neuroscience 2008; 28(44): 11240-49. doi: 10.1523/jneurosci. 2297-08.2008.

49. Peretz A, Degani N, Nachman R, Uziyel Y, Gibor G, Shabat D. et al. Meclofenamic acid and diclofenac, novel templates of KCNQ2/Q3 potassium channel openers, depress cortical neuron activity and exhibit anticonvulsant properties. Molecular pharmacology 2005; 67(4): 1053-66. doi: 10.1124/mol. 104.007112.

50. Rocha-González HI, Mao S, Alvarez-Leefmans FJ. $\mathrm{Na}+\mathrm{K}+$ 2Cl- cotransport and intracellular chloride regulation in rat primary sensory neurons: thermodynamic and kinetic aspects. Journal of Neurophysiology 2008; 100(1): 169-84. doi: 10.1152/jn.01007. 2007.

51. Hegle AP, Marble DD, Wilson GF. A voltage-driven switch for ion-independent signaling by ether-a-go-go K+ channels. Proc Natl Acad Sci U S A 2006; 103(8): 2886-91. doi: 10.1073/ pnas.0505909103

52. Watson M, Abbott KC, Yuan CM. Damned if you do, damned if you don't: potassium binding resins in hyperkalemia. Clin $\boldsymbol{J}$ Am Soc Nephrol 2010; 5(10):1723-6. doi: 10.2215/cjn.03700410.

53. 2005 International Consensus on Cardiopulmonary Resuscitation and Emergency Cardiovascular Care Science with Treatment Recommendations. Part 2: Adult basic life support. Resuscitation 2005; 67(2-3): 187-201. doi: 10.1016/j.resuscitation.2005.09.0 16.
54. Saxena K. Clinical features and management of poisoning due to potassium chloride. Med Toxicol Adverse Drug Exp 1989; 4(6): 429-43. doi: 10.1007/bf03259924.

55. Verkaik-Kloosterman J, McCann MT, Hoekstra J, Verhagen $\mathrm{H}$. Vitamins and minerals: issues associated with too low and too high population intakes. Food \& Nutrition Research 2012; 56. doi: 10.3402/fnr.v56i0.5728.

56. Elmadfa I. 7. Energy and Nutrient Intake in the European Union Based on National Data. In: European Nutrition and Health Report 2009. vol. 62. Karger Publishers; 2009; 68-156. doi: $10.1159 / 000242372$

57. Organization WH. Preventing chronic diseases: a vital investment. World Health Organization; 2005.

58. CE W. Potassium in the etiology of rheumatoid arthritis and heart infarction. Journal of Applied Nutrition 1974; 26: 41-67. doi: $10.1136 / \mathrm{bm}$.

59. Rastmanesh R, Abargouei AS, Shadman Z, Ebrahimi AA, Weber CE. A pilot study of potassium supplementation in the treatment of hypokalemic patients with rheumatoid arthritis: a randomized, double-blinded, placebo-controlled trial. The Journal of Pain 2008; 9(8): 72231. doi: 10.1016/j.jpain.2008.03. 006.

60. Rastmanesh R. Hypothetical hormonal mechanism by which potassium-rich diets benefit patients with rheumatoid arthritis. Medical Hypotheses 2009; 73(4): 564-68. doi: 10.1016/j.mehy. 2009.05.035.

61. Kant AK, Graubard BI, Kumanyika SK. Trends in blackwhite differentials in dietary intakes of US adults, 1971-2002. American Journal of Preventive Medicine 2007; 32(4): 264-72. doi: $\quad 10.1016 /$ j.amepre.2006.12. 011.

62. Cockel R, Kendall M, Becker J, Hawkins C. Serum biochemical values in rheumatoid disease. Annals of the Rheumatic Diseases 1971; 30(2): 166. doi: 10.1136/ard.3.2.166

63. Syrjänen $S$, Lappalainen $R$, Markkanen H. Salivary and serum levels of electrolytes and 
immunomarkers in edentulous healthy subjects and in those with rheumatoid arthritis. Clinical Rheumatology 1986; 5(1):49-55. doi: 10.1007/bf02030967.

64. Kianifard T, Saluja M, Chopra A. $\mathrm{AB} 1112$ Is dietary potassium important in rheumatoid arthritis? preliminary observations. Annals of the Rheumatic Diseases 2014; 73(Suppl 2): 1169-70. doi: 10.1136/annrheumdis-2014-eular. 3712.

65. Wasserman AM. Diagnosis and management of rheumatoid arthritis. American family physician 2011; 84 (11).

66. Metsios GS, StavropoulosKalinoglou A, Panoulas VF, Koutedakis Y, Nevill AM, Douglas KM. et al. New resting energy expenditure prediction equations for patients with rheumatoid arthritis. Rheumatology (Oxford) 2008; 47(4): 500-6. doi: 10.1093/ rheumatology/ken022.

67. Summers GD, Deighton CM, Rennie MJ, Booth AH. Rheumatoid cachexia: a clinical perspective. Rheumatology (Oxford) 2008; 47(8): 1124-31. doi: $\quad 10.1093 /$ rheumatology/ ken146.

68. Walsmith J, Roubenoff $\mathrm{R}$. Cachexia in rheumatoid arthritis. Int J Cardiol 2002; 85(1): 89-99.

69. Chang X, Wei C. Glycolysis and rheumatoid arthritis. Int J Rheum Dis 2011; 14(3): 217-22. doi 10.1111/j.1756-185X. 2011.01598.x

70. Weber CE. Corticosteroid regulation of electrolytes. Journal of Theoretical Biology 1983; 104(3): 443-49. doi: 10. 1016/0022-5193(83)90116-9.

71. Wulff H, Calabresi PA, Allie R, Yun S, Pennington M, Beeton C. et al. The voltage-gated Kv1. 3 $\mathrm{K}+$ channel in effector memory $\mathrm{T}$ cells as new target for MS. The Journal of Clinical Investigation 2003; 111(11): 1703-13. doi: 10. 1172/jci200316921e.

72. Cuzzocrea S. Role of nitric oxide and reactive oxygen species in arthritis. Current Pharmaceutical Design 2006; 12(27): 3551-70. doi: $10.1007 / 978-3-0348-8241$ 5_9.

73. McCabe RD, Bakarich MA, Srivastava K, Young DB.
Potassium inhibits free radical formation. Hypertension 1994; 24(1): 77-82. doi: 10.1161/01. hyp.24.1.77.

74. Nuki G, Boddy K, Kennedy AC, King P, Duncan AM, Buchanan WW. Potassium metabolism in patients with rheumatoid arthritis. Effects of treatment with depot tetracosactrin, spironolactone, and oral supplements of potassium chloride. Annals of the Rheumatic Diseases 1975; 34(6): 506-14. doi: 10.1136/ard.34.6. 506.

75. Nuki G, Jasani MK, Wilson Downie W, Whaley K, Carson Dick W, Williamson J. et al. Clinico-pharmacological studies on depot tetracosactrin in patients with rheumatoid arthritis. European Journal of Clinical Pharmacology 1970; 2(2): 99108. doi: 10.1007/bf00420715.

76. Cutolo M, Sulli A, Pizzorni C, Craviotto C, Straub R. Hypothalamic-pituitaryadrenocortical and gonadal functions in rheumatoid arthritis. Annals of the New York Academy of Sciences 2003; 992(1): 107-17. doi: 10.1111/ j.1749-6632.2003.tb03142.x.

77. Schmidt M, Weidler C, Naumann $\mathrm{H}$, Anders S, Schölmerich J, Straub RH. Reduced capacity for the reactivation of glucocorticoids in rheumatoid arthritis synovial cells: possible role of the sympathetic nervous system? Arthritis \& Rheumatism 2005; 52(6): 1711-20. doi: 10.1002/art. 21091

78. John J, Ziebland S, Yudkin P, Roe L, Neil H. Effects of fruit and vegetable consumption on plasma antioxidant concentrations and blood pressure: a randomised controlled trial. The lancet 2002; 359 (9322): 1969-74. doi: 10.1016/s0140-6736(02)98858-6.

79. Kotchen TA, Cowley Jr AW, Frohlich ED. Salt in health and disease - a delicate balance. New England Journal of Medicine 2013; 368(13): 1229-37. doi: 10. 1016/j.nut.2013.11.010

80. Aaron KJ, Sanders PW: Role of dietary salt and potassium intake in cardiovascular health and disease: a review of the evidence. In: Mayo Clinic Proceedings: 2013: Elsevier;
2013: 987-95. doi: 10.1016/j. mayocp.2013.06.005.

81. Appel LJ, Moore TJ, Obarzanek E, Vollmer WM, Svetkey LP, Sacks FM. et al. A clinical trial of the effects of dietary patterns on blood pressure. New England Journal of Medicine 1997; 336(16): 1117-24. doi: 10.1056/ NEJM199704173361601.

82. Haddy FJ, Vanhoutte PM, Feletou M. Role of potassium in regulating blood flow and blood pressure. American Journal of Physiology-Regulatory,

Integrative and Comparative Physiology 2006; 290(3): R546R52. doi: 10.1152/ajpregu.00491. 2005.

83. Ophir O, Peer G, Gilad J, Blum M, Aviram A. Low blood pressure in vegetarians: the possible role of potassium. The American Journal of Clinical Nutrition 1983; 37(5): 755-62.

84. Adrogué HJ, Madias NE. Sodium and potassium in the pathogenesis of hypertension. New England Journal of Medicine 2007; 356(19): 1966-78. doi: 10.1056/ NEJMra064486.

85. Dougados $\mathrm{M}$, Soubrier $\mathrm{M}$, Antunez A, Balint P, Balsa A, Buch MH. et al. Prevalence of comorbidities in rheumatoid arthritis and evaluation of their monitoring: results of an international, cross-sectional study (COMORA). Annals of the Rheumatic Diseases 2014; 73(1): 62-68. doi: 10.1136/annrheumdis2013-204223.

86. Tucker KL, Hannan MT, Chen H, Cupples LA, Wilson PW, Kiel DP. Potassium, magnesium, and fruit and vegetable intakes are associated with greater bone mineral density in elderly men and women. The American Journal of Clinical Nutrition 1999; 69(4): 727-36.

87. Frassetto L, Morris Jr RC, Sebastian A. Long-term persistence of the urine calciumlowering effect of potassium bicarbonate in postmenopausal women. The Journal of Clinical Endocrinology \& Metabolism 2005; 90(2): 831-34. doi: 10.1210/jc. 2005-0662.

88. Jehle S, Hulter HN, Krapf R. Effect of potassium citrate on bone density, microarchitecture, 
and fracture risk in healthy older adults without osteoporosis: a randomized controlled trial. The Journal of Clinical Endocrinology \& Metabolism 2012; 98(1): 207-17. doi: 10.1210/jc.2012-3099.

89. Macdonald HM, New SA, Golden MH, Campbell MK, Reid DM. Nutritional associations with bone loss during the menopausal transition: evidence of a beneficial effect of calcium, alcohol, and fruit and vegetable nutrients and of a detrimental effect of fatty acids. The American Journal of Clinical Nutrition 2004; 79(1): 155-65.

90. Booth SL, Tucker KL, Chen H, Hannan MT, Gagnon DR, Cupples LA. et al. Dietary vitamin $\mathrm{K}$ intakes are associated with hip fracture but not with bone mineral density in elderly men and women. The American Journal of Clinical Nutrition
2000; 71(5): 1201-08.

91. Macdonald HM, Black AJ, Aucott L, Duthie G, Duthie S, Sandison R. et al. Effect of potassium citrate supplementation or increased fruit and vegetable intake on bone metabolism in healthy postmenopausal women: a randomized controlled trial. The American Journal of Clinical Nutrition 2008; 88(2): 465-74. 